\title{
Fuse-binding protein 1 is a target of the EZH2 inhibitor GSK343, in osteosarcoma cells
}

\author{
XIFENG XIONG, JINLI ZHANG, WEIGUO LIANG, WENJUAN CAO, \\ SHENGNAN QIN, LIBING DAI, DONGPING YE and ZHIHE LIU \\ Guangzhou Institute of Traumatic Surgery, Guangzhou Red Cross Hospital, \\ Medical College, Jinan University, Guangzhou, Guangdong 510220, P.R. China
}

Received April 1, 2016; Accepted May 17, 2016

DOI: 10.3892/ijo.2016.3541

\begin{abstract}
Osteosarcoma is the primary cancer of leaf tissue and is regarded as a differentiation disease caused by genetic and epigenetic changes which interrupt the osteoblast differentiation from mesenchymal stem cells. Because of its high malignancy degree and rapid development, the morbidity and mortality are high. The enhancer of zeste homolog 2 (EZH2) is a catalytic subunit of polycomb repressive complex 2 (PRC2) and has been demonstrated to be involved in a variety of biological processes, such as cell proliferation and program cell death. EZH2 impairs gene expression by catalyzing the tri-methylation of histone $\mathrm{H} 3$ lysine 27 (H3K27me3) which controls gene transcription epigenetically. It is reported that EZH2 expression is higher in osteosarcoma than in osteoblastoma and the highest expression of EZH2 is found in osteosarcoma with metastasis. In the past few years, several potent inhibitors of EZH2 have been discovered, and GSK343 is one of them. In this study, we found that GSK343 inhibited osteosarcoma cell viability, restrained cell cycle transition and promoted programmed cell death. GSK343 not only inhibited the expression of EZH2 and its target, c-Myc and $\mathrm{H} 3 \mathrm{~K} 27 \mathrm{me}$, but it also inhibited fuse binding protein 1 (FBP1) expression, another c-Myc regulator. Furthermore, we found that FBP1 physically interacts with EZH2. Based on these results, we believe that GSK343 is a potential molecule for osteosarcoma clinical treatment. Other than the inhibition on EZH2-c-Myc signal pathway, we postulate that the inhibition on FBP1-c-Myc signal pathway is another potential underlying mechanism with which GSK343 inhibits osteosarcoma cell viability.
\end{abstract}

Correspondence to: Dr Zhihe Liu, Guangzhou Institute of Traumatic Surgery, Guangzhou Red Cross Hospital, Medical College, Jinan University, 396 Tongfu Zhong Road, Guangzhou, Guangdong 510220, P.R. China

E-mail: zliu0731@163.com

Key words: osteosarcoma, enhancer of zeste homolog 2, fuse binding protein 1 , c-Myc

\section{Introduction}

Osteosarcoma is the primary cancer of leaf tissue, which mostly occurs in the long bone metaphysis of teenagers, especially in the distal femur and proximal tibia. Because of its high malignancy degree and rapid development, the morbidity and mortality are high. Emerging evidence suggests that osteosarcoma should be regarded as a differentiation disease caused by genetic and epigenetic changes which interrupt the osteoblast differentiation from mesenchymal stem cells (1), but the specific pathological processes and molecular mechanism remains unclear.

The enhancer of zeste homolog 2 (EZH2) is a catalytic subunit of polycomb repressive complex 2 (PRC2) and is upregulated in different human cancers, such as osteosarcoma (2), prostate cancer (3), breast cancer (4) and liver cancer (5). EZH2 has been demonstrated to be involved in a variety of biological processes, such as cell proliferation and program cell death (6). It has been suggested that EZH2 contributes to gene silencing by mediating DNA methylation and histone modifications (7).EZH2 impairs gene expression by catalyzing the tri-methylation of histone $\mathrm{H} 3$ lysine 27 (H3K27me3) that interacts with its target genes $(8,9)$. H3K27me3 is supposed to be a repressive histone modification to control gene transcription epigenetically. Prior studies have shown that c-Myc co-expression with EZH2 is used in determining the prognosis of prostate cancer patients after surgery (10) and confirmed that c-Myc is a direct target of EZH2 in glioblastoma cancer stem cells (11). EZH2 induces c-Myc expression via the inhibition of Myc targeting miR-494 (12,13). As feedback, c-Myc contributes to EZH2 upregulation via the repression of EZH2 targeting miR-26a $(12,13)$. Thus EZH2 and c-Myc regulate each other in a loop manner.

c-Myc is one of the most commonly overexpressed oncogenes in cancer (14) and is a transcription factor involved in DNA replication, cell proliferation, protein synthesis, chromatin structure, differentiation and stem cell fate by regulating target gene expressions (14-16). Except EZH2, the far upstream element (FUSE) binding protein 1 (FBP1) is another critical regulator of c-Myc and was discovered because of its functions on c-Myc (17). FBP1 is a single stranded DNA and RNA-binding protein that plays an important role in cell proliferation, survival, metastasis and RNA virus replication 
(18-24). Aberrant expression of FBP1 has been found in a variety of malignant tissues $(25,26)$, including in ovarian cancer tissue (our unpublished data).

In the past few years, several potent inhibitors of EZH2 have been discovered. Roughly, they can be divided into S-adenosyl-L-homocysteine (SAH) hydrolase inhibitor, such as 3-deazaneplanocin A (DZNep); or S-adenosyl-L-methionine (SAM) competitive inhibitor, such as GSK343 (27,28). SAM is a universal methyl donor for catalytic reaction of histone methyltransferase $(28,29)$.

In order to increase our understanding on GSK343 as a molecule for clinical osteosarcoma treatment, we investigated the influence of GSK343 on cell viability and program cell death in osteosarcoma cells and the potential mechanisms underlying its activity. We found that GSK343 treatment inhibited cell viability and promotes programmed cell death of the osteosarcoma cells. Attenuating EZH2 and FBP1 expression are potential underlying mechanisms.

\section{Materials and methods}

Cell culture. Human osteosarcoma cells, Saos2, were cultured in complete Dulbecco's modified Eagle's medium (DMEM) supplemented with $10 \%(\mathrm{v} / \mathrm{v})$ fetal bovine serum (FBS), $2 \mathrm{mmol} / 1 \mathrm{~L}$-glutamine, $100 \mathrm{U} / \mathrm{ml}$ penicillin, $100 \mu \mathrm{g} / \mathrm{ml}$ streptomycin. All cells were maintained at $37^{\circ} \mathrm{C}$ and $5 \% \mathrm{CO}_{2}$ in a humidified incubator.

Antibodies and reagents. LC3, H3K27me3, GAPDH antibodies were purchased from Cell Signaling Technology (Danvers, MA, USA). EZH2 antibody was obtained from BD Technology (Research Triangle Park, NA, USA). All antibodies were used at the concentrations recommended by the supplier. DMEM medium, FBS and L-glutamine were obtained from Gibco (Gaithersburg, MD, USA). GSK343, FBP1, c-Myc and 3-methyladenine (3-MA) were provided by Sigma Chemical (St. Louis, MO, USA). The CellTiter $96^{\circledR}$ AQueous One Solution proliferation assay kit (3-(4,5-dimethylthiazol-2-yl)-5-(3-carboxymethoxyphenyl)2-(4-sulfophenyl)-2H-tetrazolium, inner salt; MTS) was purchased from Promega (Madison, WI, USA). Penicillin and streptomycin sulfate were purchased from Hyclone (Logan, UT, USA).

Cell viability assay. Saos- 2 cells were seeded at $5.0 \times 10^{3}$ cells/ well in a 96-well plate and treated with different concentrations of GSK343 for $48 \mathrm{~h}$. Cell viability was then measured using the MTS assay following the manufacturer's manual. The absorbance at $490 \mathrm{~nm}$ was measured on a 96-well plate reader. The experiment was repeated at least three times.

Flow cytometric analysis. Flow cytometry was used for cell cycle distribution analysis and apoptosis detection. For apoptosis detection, the Saos-2 cells were cultured in 6-well plates. After $48 \mathrm{~h}$ of treatment with different concentrations of GSK343, cells were collected and incubated with Annexin V-fluorescein isothiocyanate (FITC) (Beijing Biosea Biotechnology Co., Ltd., Beijing, China) for $30 \mathrm{~min}$ at $4^{\circ} \mathrm{C}$ in the dark, and then incubated with propidium iodide (PI) (Beijing Biosea Biotechnology Co., Ltd.) for $5 \mathrm{~min}$.
Analysis was immediately performed by flow cytometry (FACSAria II, Becton-Dickinson, Franklin Lakes, NJ, USA). For cell cycle analysis, the Saos-2 cells were trypsinized and fixed in $70 \%(\mathrm{v} / \mathrm{v})$ ethanol overnight at $4^{\circ} \mathrm{C}$. Then cells were collected and resuspended in phosphate-buffered saline (PBS) containing $50 \mu \mathrm{g} / \mathrm{ml}$ of PI. Cell cycle analyses were performed using FACS Aria II (Becton-Dickinson).

Western blot analysis. Cells were lysed for western blotting in modified RIPA buffer [150 mmol/1 NaCl, $1 \% \mathrm{NP}-40$, $50 \mathrm{mmol} / 1$ Tris-Cl (pH 8.0), 0.1\% SDS] supplemented with protease and phosphatase inhibitor, PMSF (1 mmol/l). After rapid homogenization, the homogenate was incubated in ice for $30 \mathrm{~min}$ and centrifuged at $12,000 \mathrm{~g}$ for $15 \mathrm{~min}$ at $4^{\circ} \mathrm{C}$. Protein concentration was determined by bicinchoninic acid protein assay (Pierce, MO, USA). The protein samples (30-50 $\mu \mathrm{g}$ ) were resolved by SDS-PAGE (12\%) and transferred to PVDF membranes (Millipore, Boston, MI, USA). Following transfer, membranes were blocked with 5\% skim milk in TBS-Tween (0.05 M Tris, $0.15 \mathrm{M} \mathrm{NaCl}, \mathrm{pH} 7.5$, and $0.2 \%$ Tween-20) for $1 \mathrm{~h}$, and then incubated at $4^{\circ} \mathrm{C}$ overnight with primary antibodies. Membranes were incubated with anti-rabbit/mouse HRP-labeled secondary antibodies for $1 \mathrm{~h}$ at room temperature after washing, and detected with ECL-Plus (Pierce). Relative abundance was quantified by densitometry using Quantity One 4.6.7 software (Bio-Rad, Philadelphia, PA, USA).

Laser confocal immunofluorescence microscopy. The cells were treated with different concentrations (0-20 $\mu \mathrm{mol} / \mathrm{l})$ of GSK343 for $48 \mathrm{~h}$, and then fixed in $4 \%$ paraformaldehyde (PFA) for 15 min, washed in PBS, blocked using 10\% normal goat serum, and incubated with a 1:100 dilution of rabbit polyclonal antibody against LC3 overnight at $4^{\circ} \mathrm{C}$. FITCconjugated anti-rabbit IgG were applied at a 1:200 dilution for $1 \mathrm{~h}$. The cells were counterstained with DAPI and observed immediately using a Zeiss confocal microscope (Oberkochen, Germany).

Co-immunoprecipitation (Co-IP). Cultured Saos-2 cells were collected in lysis buffer $(150 \mathrm{mmol} / 1 \mathrm{NaCl}, 50 \mathrm{mmol} / \mathrm{l}$ Tris-HCl, 1 mmol/1 EDTA, pH 7.5, 1\% NP-40) containing protease inhibitor (Roche, CA, USA) and kept in ice for $30 \mathrm{~min}$ after washed twice with PBS. After sonication and centrifugation, the whole-cell lysate was made. Whole-cell lysates were incubated with either anti-EZH2 antibody or IgG (Abcam, Cambridge, UK) at $4^{\circ} \mathrm{C}$ with rotation for $2 \mathrm{~h}$, then were incubated with prepared Protein $\mathrm{A}+\mathrm{G}$ agarose beads (Santa Cruz, CA, USA) at $4^{\circ} \mathrm{C}$ overnight. The precipitations were washed four times with lysis buffer, and were eluted in SDS-PAGE loading buffer by boiling for $5 \mathrm{~min}$. The supernatants were then resolved by SDS-PAGE and transferred to PVDF membranes. Immunoblotting using appropriate antibodies was conducted using standard protocol.

Statistical analysis and data presentation. All data shown represented one of at least three independent experiments and were expressed as mean \pm SD. Statistics was performed using Students't test. $\mathrm{P}<0.05$ was considered statistically significant difference. 
A
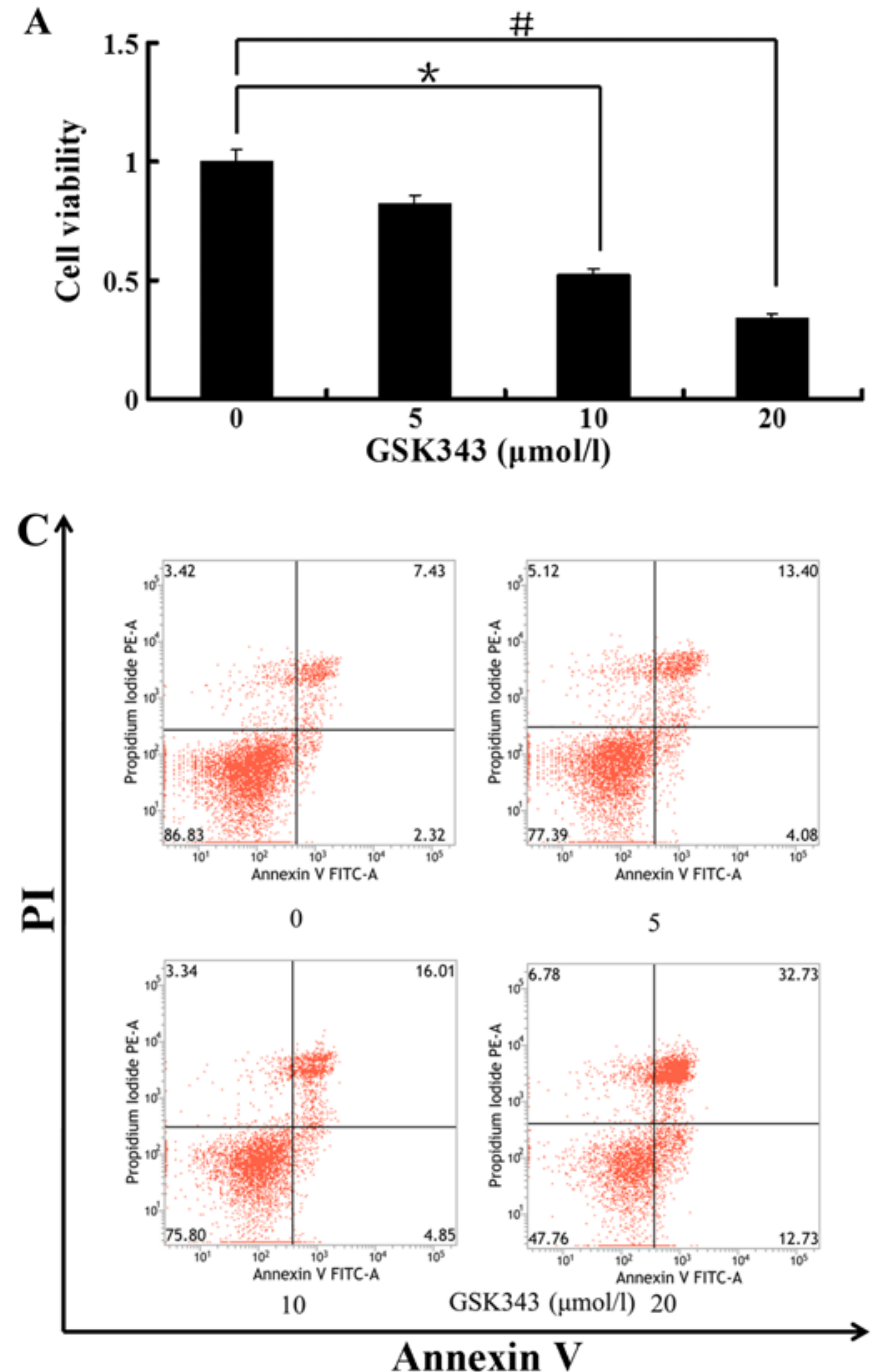

B

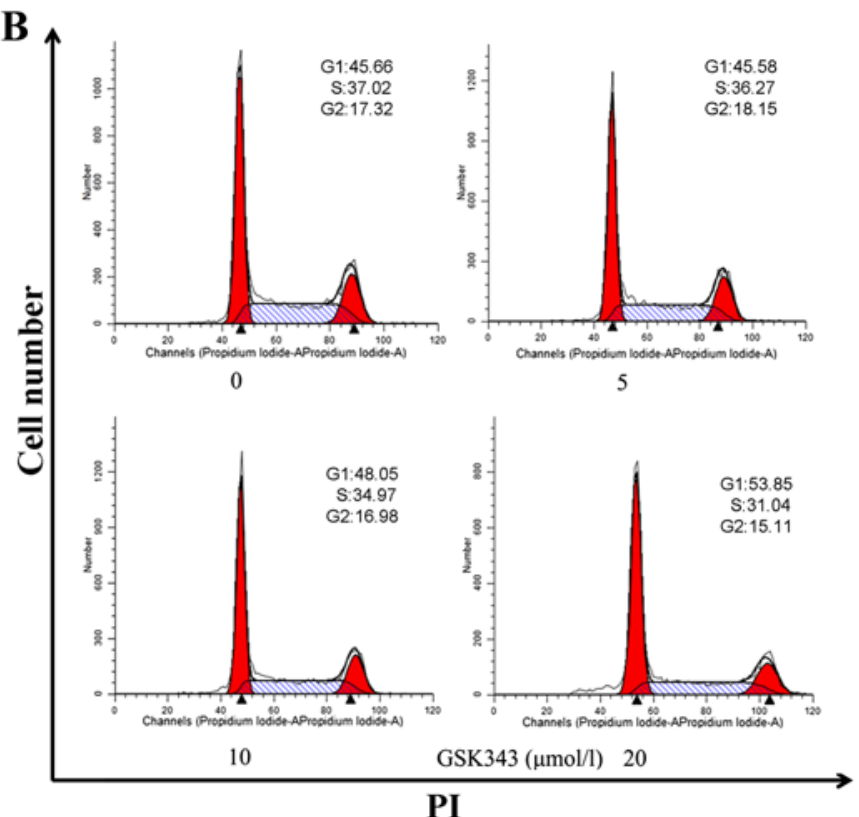

D

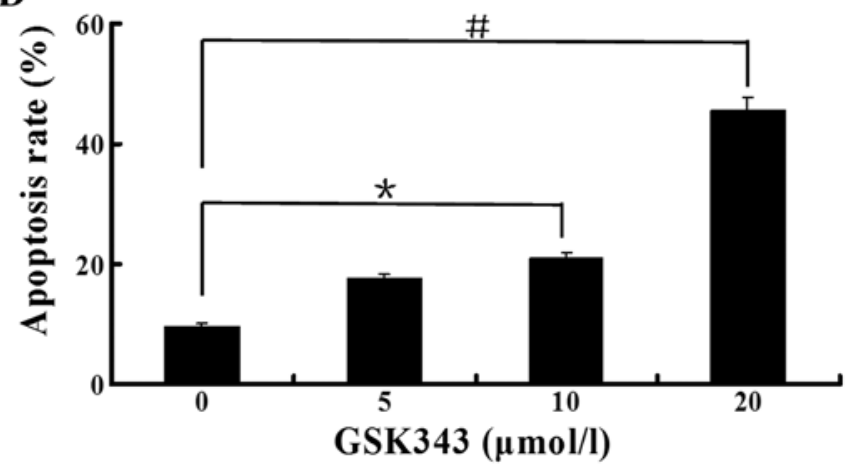

Figure 1. The effects of GSK343 on the cell viability, cell cycle and apoptosis of Saos-2 cells. (A) Cell viability of Saos-2 which was treated for $48 \mathrm{~h}$ at indicated concentrations by MTS assay; (B) G1-S-G2-phase of Saos-2 detected by flow cytometry. Cells were incubated with GSK343 at indicated concentrations for $48 \mathrm{~h}$. The untreated cells ( 0 ) were used as a control; (C) Apoptotic Saos-2 cells were detected by the Annexin V/PI assay after treated with GSK343 for $48 \mathrm{~h}$ at indicated concentrations and apoptosis rates were present in (D). Using this assay, the viable (Annexin $\mathrm{V}^{-} / \mathrm{PI}^{-}$), early apoptotic (Annexin $\left.\mathrm{V}^{+} / \mathrm{PI}^{-}\right)$, late apoptotic or necrotic cells (Annexin $\mathrm{V}^{+} / \mathrm{PI}^{+}$) were classified. Data are presented as mean $\pm \mathrm{SD}(\mathrm{n}=3)$. ${ }^{*} \mathrm{P}<0.05,{ }^{,} \mathrm{P}<0.01$ compared with the control $(0 \mu \mathrm{mol} / 1$ of GSK343). Data shown are representative of a minimum of three independent experiments.

\section{Results}

GSK343 inhibits the viability of osteosarcoma Saos-2 cells. We assessed the effect of GSK343 on the viability of osteosarcoma Saos-2 cells. Cell viability was examined with MTS assay. Ten and $20 \mu \mathrm{mol} / 1$ of GSK343 inhibited significantly Saos-2 cell viability, and the cell viability decreased to 52 and $34 \%$ for 10 and $20 \mu \mathrm{mol} / 1$ of GSK343, respectively (Fig. 1A). GSK343 inhibited cell viability in a dose-dependent manner by the concentration of $20 \mu \mathrm{mol} / 1$.

GSK343 induces cell cycle arrest and apoptosis in osteosarcoma Saos-2 cells. In order to elucidate the factors which decreased cell viability, we investigated cell cycle transition and apoptosis, namely type I programmed cell death, in Saos-2 cells treated with GSK343 by flow cytometry. A significant elevation in G1-phase and an evident decline in S-phase cells were observed (Fig. 1B). GSK343 (20 $\mu \mathrm{mol} / \mathrm{l})$ increased the percentage of G1-phase Saos-2 cells from 45.66 to $53.85 \%$ $(\mathrm{p}<0.05)$, and reduced the percentage of S-phase and G2-phase cells from 37.02 to $31.04 \%$, and 17.32 to $15.11 \%$, respectively. These data indicated that GSK343 blocked Saos-2 cell cycle progression at the G1-phase and inhibited DNA synthesis.

The Annexin V-FITC/PI assay revealed that GSK343 treatment significantly enhanced Saos-2 apoptosis comparing with the untreated Saos- 2 cells. Treatment with $20 \mu \mathrm{mol} / 1$ of GSK343 increased apoptosis 4.6-fold (Fig. 1C and D, p<0.01). These data indicated that GSK343 induced apoptosis.

GSK343 induces autophagy in osteosarcoma Saos-2 cells. Autophagic cell death is another important programmed cell death and is known as type II program cell death. It plays an important role in cell fate. LC3, a hallmark of mammalian autophagy, is essential for the formation of autophagosomes and for the completion of macroautophagy (30). LC3-II is an LC3-phosphatidylethanolamine conjugate and a promising 
A
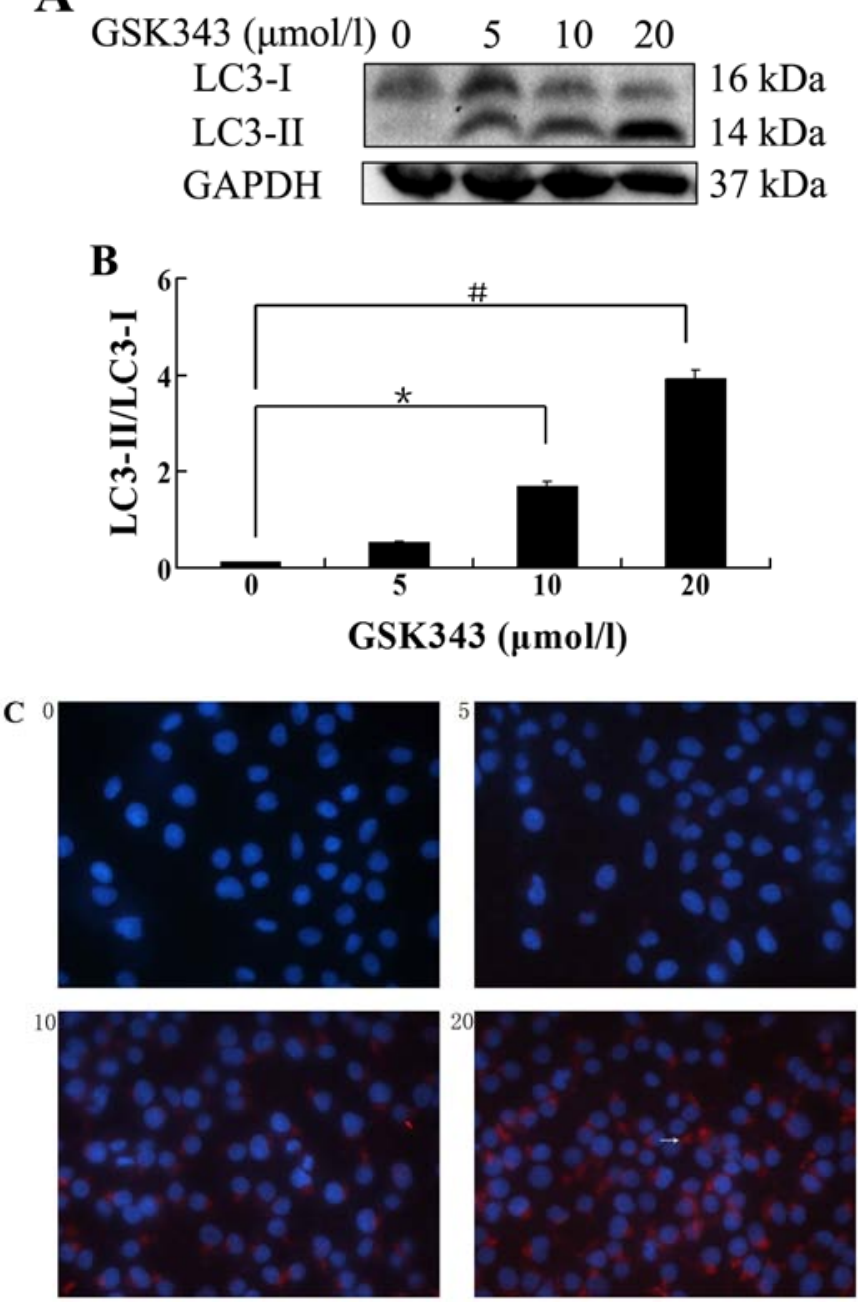

D

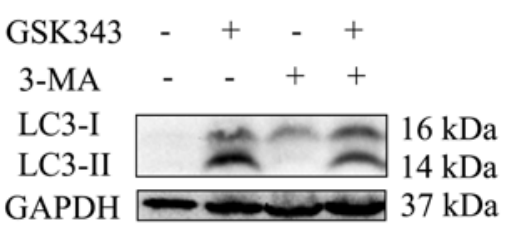

E

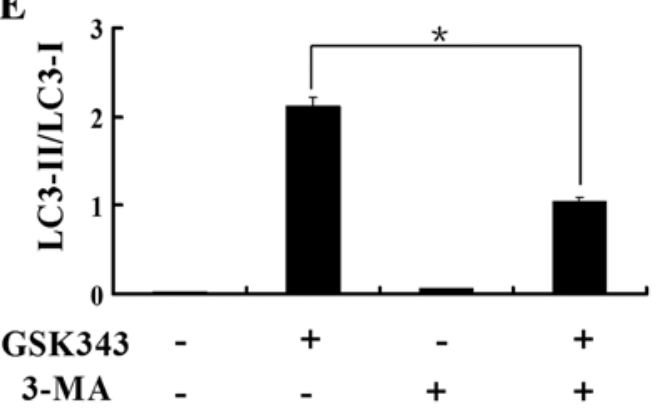

Figure 2. GSK343 induces autophagic cell death in Saos-2 cells. (A) LC3-I and -II expressions and LC-II/LC-I ratios (B) in Saos-2 cells treated with GSK343 for $48 \mathrm{~h}$ at indicated concentration detected by western blot assay. GAPDH was used as the loading control; (C) LC3-II puncta formation in Saos-2 cells treated with GSK343 for $48 \mathrm{~h}$ at indicated concentration tested by immunofluorescence staining assay. Images were co-stained with nuclear dye DAPI and observed immediately using a Zeiss confocal microscope (magnification, $\mathrm{x} 400$ ). Arrow indicates one of LC-II puncta; (D) 3-MA attenuated LC3-II expression and LC-II/LC-I ratios (E) in GSK343-treated Saos- 2 cells. 3-MA was added to Saos- 2 cells $2 \mathrm{~h}$ before GSK treatment. Cell lysates were collected after $48 \mathrm{~h}$ of GSK343 treatments and subjected to western blot analysis.
A

\begin{tabular}{|c|c|c|c|c|c|}
\hline SK343 $(\mu \mathrm{mo}$ & 0 & 5 & 10 & 20 & \\
\hline EZH2 & $=$ & $=$ & - & 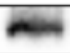 & 98 \\
\hline H3К 27 & $=$ & $=$ & moss & me & 17 \\
\hline $\mathrm{GA}$ & $=$ & & - & 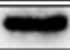 & 37 \\
\hline
\end{tabular}

B GSK343 $(\mu \mathrm{mol} / \mathrm{l}) 0 \quad 5 \quad 10 \quad 20$
FBP1
c-Myc
GAPDH

C
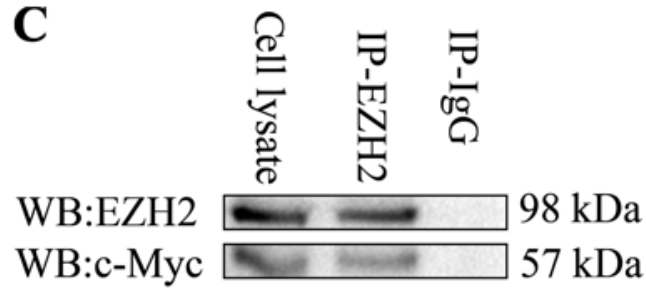

D
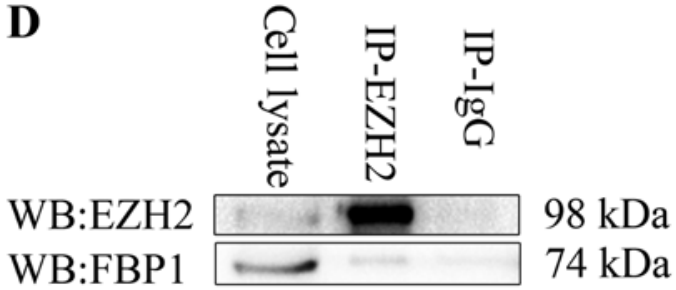

Figure 3. The effects of GSK343 on associated protein expressions in Saos-2 cells. (A) The expression of EZH2, H3K27me3 and (B) c-Myc, FBP1 in Saos-2 cells treated with GSK343. Saos-2 cells were treated with 0, 5, 10 and $20 \mu \mathrm{mol} / 1$ of GSK343 for $48 \mathrm{~h}$. Whole-cell lysates were subjected to western blot analysis. GAPDH acted as a loading control. (C) The physical interaction between EZH2 and c-Myc detected by Co-IP assay. (D) The physical interaction between FBP1 and EZH2 detected by Co-IP assay.

autophagosomal marker (31). Since the conversion rate of LC3-I to LC3-II is a hallmark of mammalian autophagy, we examined the expression of LC3-I and LC3-II and the conversion rate of LC3-I to LC3-II. As shown in Fig. 2A and B, western blot analysis showed that LC3-II was significantly upregulated by GSK343 treatment in a dose-dependent manner from 5 to $20 \mu \mathrm{mol} / 1$. Furthermore, immunofluorescence assay confirmed LC3-II puncta formation (red staining, Fig. 2C). Same as the results of western blot analysis, GSK343 also promoted LC3-II puncta formation in a dose-dependent manner.

3-MA has been identified as a classical autophagy inhibitor (32) and widely used in pharmacokinetic studies of autophagy. To investigate the effects of 3-MA on GSK343-induced autophagy, we treated Saos-2 cells with $5 \mathrm{mmol} / \mathrm{l}$ of $3-\mathrm{MA}$ for $2 \mathrm{~h}$ before the treatment of $20 \mu \mathrm{mol} / \mathrm{l}$ of GSK343. Western blot analysis showed that 3-MA attenuated GSK343-induced LC3-II accumulation while 3-MA alone had no any effect on LC3-II accumulation (Fig. 2D and E). This result implied that 3-MA treatment significantly attenuated GSK343-induced autophagy. Combined together, these findings indicate that GSK343 treatment induces autophagic cell death in Saos-2 cells. 
GSK343 reduces the expression of $\mathrm{EZH} 2, \mathrm{H} 3 \mathrm{~K} 27 \mathrm{me} 3$ and c-Myc in Saos-2 cells. The expression of EZH2 protein was tested in GSK343 untreated and treated Saos-2 cells. As shown in Fig. 3A, GSK343 reduced the expression of EZH2 protein in a dose-dependent manner. In addition, we investigated the expression of EZH2 target protein, H3K27me3, which was also reduced by GSK343 in a dose-dependent manner.

A recent study demonstrated that EZH2 promoted c-Myc expression by attenuating miR-494 which was shown to inhibit c-Myc expression in aggressive B-cell lymphomas (13). Here, we found that GSK343 not only inhibited EZH2 expression, but also inhibited c-Myc expression (Fig. 3B). In addition, we confirmed the physical interaction between EZH2 and c-Myc by Co-IP assay. As shown in Fig. 3C, immunoblot assay detected c-Myc in EZH2 antibody pull-down solution.

GSK343 attenuates FBP1 expression. As we know, FBP1 was discovered because its function on c-Myc expression. FBP1 promotes c-Myc expression by binding with the c-Myc promoter. We found that GSK343 treatment decreased FBP1 expression in Saos-2 cells in a dose-dependent manner (Fig. 3B).

Since c-Myc is the target of EZH2 and FBP1, we wished to clarify the relationship between EZH2 and FBP1. With the Co-IP assay, we also confirmed the physical interaction between EZH2 and FBP1 (Fig. 3D).

\section{Discussion}

EZH2, the catalytic subunit of polycomb repressive complex 2 (PRC2), catalyzes trimethylation of lysine 27 on histone $\mathrm{H} 3$ (H3K27me3) and mediates transcriptional silencing $(33,34)$. H3K27 trimethylation suppresses transcription of specific genes that are proximal to the site of histone modification (35). EZH2 is directly implicated in various cancers as well as osteosarcoma. In this study, we found that GSK343, one EZH2 methyltransferase inhibitor, inhibited osteosarcoma cell viability. This result is consistent with the finding in human hepatocellular carcinoma cells (36).

Low cell viability may be induced by cell cycle restrain and cell death activation. By flow cytometry, we found GSK343 treatment significantly suppressed cell cycle transition from G1 phase to $\mathrm{S} / \mathrm{G} 2$ phase and activated apoptosis in osteosarcoma Saos-2 cells (Figs. 1 and 2). Except for activating apoptosis, GSK343 treatment also activated autophagic cell death. As it is known, LC3 is a hallmark of autophagy that contains LC3-I and LC3-II forms. LC3-II is an LC3-phosphatidylethanolamine conjugate and a promising autophagosomal marker (31). In this study, LC3-II was significantly upregulated by GSK343 in a dose-dependent manner (Fig. 2). It was consistent with our expectation that the pretreatment with 3-MA, an autophagy inhibitor, decreased GSK343-induced autophagic cell death (Fig. 2). GSK343 treatment induced programmed cell death in osterosarcoma, including apoptosis and autophagic cell death.

As it is known, EZH2 can positively regulate c-Myc expression (37). c-Myc is a pleiotropic transcription factor that both activates and represses a broad range of target genes and is indispensable for cell growth (35). In addition, c-Myc is able to bind to the promoter of $\mathrm{EZH} 2$ and provoke $\mathrm{EZH} 2$ overexpression through suppression of miR-26a (38) and has been identified as a key regulator of EZH2 expression $(12,39)$.
In this study, we found that GSK343 treatment inhibited the expression of EZH2 and c-Myc in osteosarcoma cells. Further, we found the physical interaction between EZH2 and c-Myc.

FBP1 is a critical regulator of the proto-oncogene c-Myc through binding with the c-Myc promoter and plays important roles in cell proliferation, survival and metastasis (18). We found that GSK343 treatment not only inhibited EZH2 expression, but also inhibited FBP1 expression in osteosarcoma cells (Fig. 3). This is the first study reporting that GSK343, one of EZH2 inhibitors, inhibits FBP1 expression. Interestingly, we detected a physical interaction between EZH2 and FBP1 in vivo by Co-IP assay.

FBP1, EZH2 and c-Myc are all important cell fate regulators. It is demonstrated that FBP1-c-Myc and EZH2-c-Myc signal pathways play important roles in cell fate regulation. Combining our results, we believe that suppression of cell cycle transition and the activation of programmed cell death of GSK343 are, at least in part, through the inhibition on FBP1-c-Myc and EZH2-c-Myc signal pathways. It is reported that FBP1 promote tumor-relevant functions by at least partly employing stathmin, a microtubule-destabilizing factor $(40,41)$. On the contrary, EZH2 is reported to inhibit cofilin phosphorylation, another microtubule stabilization regulator (42). Except our finding on the physical interaction between FBP1 and EZH2, there is no other study on them. Therefore, considering the physical interaction of FBP1 and EZH2 and their functions on microtubule stabilization, it is reasonable to assume there is a link between FBP1-c-Myc and EZH2-c-Myc signal pathways. Further research regarding this connection will be meaningful.

In conclusion, our observations indicate that GSK343, the EZH2 inhibitor, is a potential molecule for osteosarcoma clinical treatment. GSK343 inhibits cancer cell viability by attenuating cell cycle promotion and promoting programmed cell death. We postulate that the inhibition of GSK343 on c-Myc, EZH2 and FBP1 is one of the potential underlying mechanisms.

\section{Acknowledgements}

This study was supported by the National Natural Science Foundation of China (nos. 81272222, to Z.L.) and Medical and Health Science and Technology Project of Guangzhou (no. 20161A010019, to X.X.). The authors would like to thank Siyu Liu from Rutgers, the State University of New Jersey, USA for her help in manuscript writing. Flow cytometry work was supported by Guangdong Provincial Key Laboratory of Malignant Tumor Epigenetics and Gene Regulation, Sun Yat-Sen Memorial Hospital, Sun Yat-Sen University.

\section{References}

1. Tang N, Song WX, Luo J, Haydon RC and He TC: Osteosarcoma development and stem cell differentiation. Clin Orthop Relat Res 466: 2114-2130, 2008.

2. Lv YF, Yan GN, Meng G, Zhang X and Guo QN: Enhancer of zeste homolog 2 silencing inhibits tumor growth and lung metastasis in osteosarcoma. Sci Rep 5: 12999, 2015.

3. Varambally S, Dhanasekaran SM, Zhou M, Barrette TR, KumarSinha C, Sanda MG, Ghosh D, Pienta KJ, Sewalt RG, Otte AP, et al: The polycomb group protein $\mathrm{EZH} 2$ is involved in progression of prostate cancer. Nature 419: 624-629, 2002. 
4. Kleer CG, Cao Q, Varambally S, Shen R, Ota I, Tomlins SA, Ghosh D, Sewalt RG, Otte AP, Hayes DF, et al: EZH2 is a marker of aggressive breast cancer and promotes neoplastic transformation of breast epithelial cells. Proc Natl Acad Sci USA 100: 11606-11611, 2003.

5. Au SL, Wong CC, Lee JM, Wong CM and Ng IO: EZH2-mediated $\mathrm{H} 3 \mathrm{~K} 27 \mathrm{me} 3$ is involved in epigenetic repression of deleted in liver cancer 1 in human cancers. PLoS One 8: e68226, 2013.

6. Simon JA and Lange CA: Roles of the EZH2 histone methyltransferase in cancer epigenetics. Mutat Res 647: 21-29, 2008.

7. Schlesinger Y, Straussman R, Keshet I, Farkash S, Hecht M, Zimmerman J, Eden E, Yakhini Z, Ben-Shushan E, Reubinoff BE, et al: Polycomb-mediated methylation on Lys27 of histone H3 pre-marks genes for de novo methylation in cancer. Nat Genet 39 : 232-236, 2007.

8. Cao R, Wang L, Wang H, Xia L, Erdjument-Bromage H, Tempst P, Jones RS and Zhang Y: Role of histone H3 lysine 27 methylation in Polycomb-group silencing. Science 298: 1039-1043, 2002.

9. Czermin B, Melfi R, McCabe D, Seitz V, Imhof A and Pirrotta V: Drosophila enhancer of Zeste/ESC complexes have a histone H3 methyltransferase activity that marks chromosomal Polycomb sites. Cell 111: 185-196, 2002.

10. Li K, Chen MK, Situ J, Huang WT, Su ZL, He D and Gao X: Role of co-expression of c-Myc, EZH2 and p27 in prognosis of prostate cancer patients after surgery. Chin Med J (Engl) 126: 82-87, 2013.

11. Suvà ML, Riggi N, Janiszewska $M$, Radovanovic I, Provero $P$, Stehle JC, Baumer K, Le Bitoux MA, Marino D, Cironi L, et al: $\mathrm{EZH} 2$ is essential for glioblastoma cancer stem cell maintenance. Cancer Res 69: 9211-9218, 2009.

12. Koh CM, Iwata T, Zheng Q, Bethel C, Yegnasubramanian S and De Marzo AM: Myc enforces overexpression of EZH2 in early prostatic neoplasia via transcriptional and post-transcriptional mechanisms. Oncotarget 2: 669-683, 2011.

13. Zhang X, Zhao X, Fiskus W, Lin J, Lwin T, Rao R, Zhang Y, Chan JC, Fu K, Marquez VE, et al: Coordinated silencing of MYC-mediated miR-29 by HDAC3 and EZH2 as a therapeutic target of histone modification in aggressive B-Cell lymphomas. Cancer Cell 22: 506-523, 2012.

14. Meyer N and Penn LZ: Reflecting on 25 years with MYC. Nat Rev Cancer 8: 976-990, 2008

15. Kuser-Abali G, Alptekin A and Cinar B: Overexpression of MYC and EZH2 cooperates to epigenetically silence MST1 expression. Epigenetics 9: 634-643, 2014

16. Dang CV, O'Donnell KA, Zeller KI, Nguyen T, Osthus RC and Li F: The c-Myc target gene network. Semin Cancer Biol 16 253-264, 2006

17. Duncan R, Bazar L, Michelotti G, Tomonaga T, Krutzsch H, Avigan $M$ and Levens D: A sequence-specific, single-strand binding protein activates the far upstream element of c-myc and defines a new DNA-binding motif. Genes Dev 8: 465-480, 1994.

18. Zhang J and Chen QM: Far upstream element binding protein 1 : A commander of transcription, translation and beyond. Oncogene 32: 2907-2916, 2013

19. Matsushita K, Tomonaga T, Shimada H, Shioya A, Higashi M, Matsubara H, Harigaya K, Nomura F, Libutti D, Levens D, et al: An essential role of alternative splicing of c-myc suppressor FUSE-binding protein-interacting repressor in carcinogenesis. Cancer Res 66: 1409-1417, 2006.

20. Zubaidah RM, Tan GS, Tan SB, Lim SG, Lin Q and Chung MC 2-D DIGE profiling of hepatocellular carcinoma tissues identified isoforms of far upstream binding protein (FUBP) as novel candidates in liver carcinogenesis. Proteomics 8: 5086-5096, 2008.

21. Dixit U, Liu Z, Pandey AK, Kothari R and Pandey VN: Fuse binding protein antagonizes the transcription activity of tumor suppressor protein p53. BMC Cancer 14: 925, 2014.

22. Dixit U, Pandey AK, Liu Z, Kumar S, Neiditch MB, Klein KM and Pandey VN: FUSE binding protein 1 facilitates persistent hepatitis $C$ virus replication in hepatoma cells by regulating tumor suppressor p53. J Virol 89: 7905-7921, 2015.

23. Zhang Z, Harris D and Pandey VN: The FUSE binding protein is a cellular factor required for efficient replication of hepatitis $\mathrm{C}$ virus. J Virol 82: 5761-5773, 2008.

24. Chien HL, Liao CL and Lin YL: FUSE binding protein 1 interacts with untranslated regions of Japanese encephalitis virus RNA and negatively regulates viral replication. J Virol 85: 4698-4706, 2011.
25. Bettegowda C, Agrawal N, Jiao Y, Sausen M, Wood LD, Hruban RH, Rodriguez FJ, Cahill DP, McLendon R, Riggins G, et al: Mutations in CIC and FUBP1 contribute to human oligodendroglioma. Science 333: 1453-1455, 2011

26. Rabenhorst U, Beinoraviciute-Kellner R, Brezniceanu ML, Joos S, Devens F, Lichter P, Rieker RJ, Trojan J, Chung HJ, Levens DL, et al: Overexpression of the far upstream element binding protein 1 in hepatocellular carcinoma is required for tumor growth. Hepatology 50: 1121-1129, 2009.

27. Tan JZ, Yan Y, Wang XX, Jiang Y and Xu HE: EZH2: Biology, disease, and structure-based drug discovery. Acta Pharmacol Sin 35: 161-174, 2014

28. Verma SK, Tian X, LaFrance LV, Duquenne C, Suarez DP, Newlander KA, Romeril SP, Burgess JL, Grant SW, Brackley JA, et al: Identification of potent, selective, cell-active inhibitors of the histone lysine methyltransferase EZH2. ACS Med Chem Lett 3: 1091-1096, 2012

29. Amatangelo MD, Garipov A, Li H, Conejo-Garcia JR, Speicher DW and Zhang R: Three-dimensional culture sensitizes epithelial ovarian cancer cells to EZH2 methyltransferase inhibition. Cell Cycle 12: 2113-2119, 2013.

30. Mizushima N, Yamamoto A, Matsui M, Yoshimori T and Ohsumi Y: In vivo analysis of autophagy in response to nutrient starvation using transgenic mice expressing a fluorescent autophagosome marker. Mol Biol Cell 15: 1101-1111, 2004.

31. Asanuma K, Tanida I, Shirato I, Ueno T, Takahara H, Nishitani T, Kominami E and Tomino Y: MAP-LC3, a promising autophagosomal marker, is processed during the differentiation and recovery of podocytes from PAN nephrosis. FASEB J 17: 1165-1167, 2003

32. Seglen PO and Gordon PB: 3-Methyladenine: Specific inhibitor of autophagic/lysosomal protein degradation in isolated rat hepatocytes. Proc Natl Acad Sci USA 79: 1889-1892, 1982.

33. Radulović V, de Haan G and Klauke K: Polycomb-group proteins in hematopoietic stem cell regulation and hematopoietic neoplasms. Leukemia 27: 523-533, 2013.

34. Popovic R and Licht JD: Emerging epigenetic targets and therapies in cancer medicine. Cancer Discov 2: 405-413, 2012.

35. Zhao X, Lwin T, Zhang X, Huang A, Wang J, Marquez VE, Chen-Kiang S, Dalton WS, Sotomayor E and Tao J: Disruption of the MYC-miRNA-EZH2 loop to suppress aggressive B-cell lymphoma survival and clonogenicity. Leukemia 27: 2341-2350, 2013.

36. Liu TP, Lo HL, Wei LS, Hsiao HH and Yang PM: S-AdenosylL-methionine-competitive inhibitors of the histone methyltransferase EZH2 induce autophagy and enhance drug sensitivity in cancer cells. Anticancer Drugs 26: 139-147, 2015.

37. Shi B, Liang J, Yang X, Wang Y, Zhao Y, Wu H, Sun L, Zhang Y, Chen Y, Li R, et al: Integration of estrogen and Wnt signaling circuits by the polycomb group protein EZH2 in breast cancer cells. Mol Cell Biol 27: 5105-5119, 2007.

38. Sander S, Bullinger L, Klapproth K, Fiedler K, Kestler HA, Barth TF, Möller P, Stilgenbauer S, Pollack JR and Wirth T: MYC stimulates EZH2 expression by repression of its negative regulator miR-26a. Blood 112: 4202-4212, 2008

39. Kaur M and Cole MD: MYC acts via the PTEN tumor suppressor to elicit autoregulation and genome-wide gene repression by activation of the Ezh2 methyltransferase. Cancer Res 73: 695-705, 2013.

40. Malz M, Weber A, Singer S, Riehmer V, Bissinger M, Riener MO Longerich T, Soll C, Vogel A, Angel P, et al: Overexpression of far upstream element binding proteins: A mechanism regulating proliferation and migration in liver cancer cells. Hepatology 50: $1130-1139,2009$

41. Singer S, Malz M, Herpel E, Warth A, Bissinger M, Keith M, Muley T, Meister M, Hoffmann H, Penzel R, et al: Coordinated expression of stathmin family members by far upstream sequence element-binding protein-1 increases motility in non-small cell lung cancer. Cancer Res 69: 2234-2243, 2009.

42. Ferraro A, Boni T and Pintzas A: EZH2 regulates cofilin activity and colon cancer cell migration by targeting ITGA2 gene. PLoS One 9: e115276, 2014. 